\title{
Perceptions of Tinnitus in a Group of Senior Citizens
}

\author{
Pamela Mae Sourgen and Eleanor Ross
}

\author{
Department of Speech Pathology and Audiology \\ University of the Witwatersrand
}

\begin{abstract}
Although previous research has highlighted the debilitating effects of tinnitus on quality of life, most studies appear to have targeted the general population, with few researchers focusing specifically on elderly persons. Hence, the purpose of this study was to investigate the perceptions of tinnitus in a group of 20 senior citizens. A questionnaire based on existing research instruments developed by Stouffer and Tyler (1990) and Wilson et al. (1991) was used to elicit information regarding the auditory-perceptual characteristics of tinnitus, effects of tinnitus on lifestyle, perceived causes, factors aggravating or ameliorating tinnitus and coping strategies employed. Results supported findings from earlier research and indicated that tinnitus did indeed exert an impact on respondents' lives with 65\% avoiding noisy situations, $65 \%$ having difficulty relaxing, and 55\% struggling to follow conversations. Almost two-thirds, namely 70\%, of respondents reported feelings of frustration, $60 \%$ and $55 \%$ mentioned feelings of tenseness and irritability respectively, while 50\% experienced depression associated with the tinnitus. These findings are discussed in terms of their implications for the education of health care professionals, management of tinnitus patients in general, public and patient awareness campaigns, the establishment of Tinnitus Self Help Groups, and further research.
\end{abstract}

\section{OPSOMMING}

Alhoewel vorige navorsing die negatiewe gevolge van tinnitus op lewenskwaliteit aangetoon het, was die meeste studies klaarblyklik gemik op die algemene bevolking, en het min navorsing op bejaardes gefokus. Derhalwe, was die doel van hierdie studie om die persepsies van tinnitus in ' $n$ groep van 20 senior burgers te ondersoek. ' $n$ Vraelys, gebaseer op bestaande navorsingmiddels ontwikkel deur Stouffer en Tyler (1990) en Wilson en andere (1991) is gebruik om inligting te verkry oor die ouditief-perseptuele kenmerke'van tinnitus op lewensstyl, waarnemende oorsake, faktore wat tinnitus vererger of verbeter, en hanterings-strategieë wat gebruik word vir die verligting / vermindering van tinnitus. Die resultate stem ooreen met dié van vorige navorsing en het aangedui dat tinnitus wel 'n invloed het op respondente se lewens, met 65\% wat lawaaierige situasies vermy, 65\% wat dit moeilik ondervind om te ontspan, en 55\% wat sukkel om gesprekke te volg. Amper twee-derdes, naamlik $70 \%$ van die respondente het gevoelens van frustrasie aangemeld, 60\% en $50 \%$ respektiewelik, het melding gemaak van gevoelens van spanning en irritasie, terwyl 50\% gevoelens van depressie as gevolg van die tinnitus ondervind het. Hierdie bevindinge word bespreek in terme van hul implikasies vir die opleiding van gesondheidsorg-personeel, die behandeling van tinnitus-pasiënte in die algemeen, veldtogte vir die bewusmaking van die publiek, die daarstelling van tinnitus-selfhelpgroepe, en verdere navorsing.

KEY WORDS: tinnitus, senior citizens, quality of life

Tinnitus is one of the most debilitating and disabling symptoms of auditory dysfunction, and despite the fact that the past 20 years have seen an enormous growth in clinical and research interest in this condition, there still appears to be no widely accepted treatment that is highly successful (Tyler, Aran \& Dauman, 1992: 41; Tyler, 1997b). The term "tinnitus" is derived from the Latin "tinnire" which means to ring or to tinkle (Jackson, 1983:159), and is used to describe "the subjective perception of sound by an individual in the ear or head unrelated to an external sound" (O'Connor \& Zappia, 1993: 25). Hence, the sound which is produced involuntarily, does not have an external source. Various ways of classifying tinnitus have been put forward, namely: middle ear and sensorineural tinnitus, pulsatile and non-pulsatile tinnitus and objective and subjective tinnitus (O’Connor \& Zappia, 1993; Tyler, 1997a). Since middle-ear tinnitus is caused by myoclonic or vascular sources (Tyler \& Babin, 1993) it has a pulsating quality. In view of the fact that the patient is hearing a part of their body external to the auditory system it is also known as objective tinnitus, which can sometimes be heard by the doctor as well (O'Connor \& Zappia, 1993). Sensorineural tinnitus, also known as non-pulsatile or subjective tinnitus, is commonly caused by noise exposure and aging which can result in either hair cell, chemical or neural abnormalities (Tyler, 1997a). However, Tyler and Babin (1993) maintain that the distinction between subjective and objective tinnitus has limited usefulness as studies of cochlear emissions have demonstrated that a sound which can be heard by the examiner in the ear 
canal, may not be heard by the patient and often originates in the inner ear (Norton, Schmidt \& Stover; 1990).

The sensation of tinnitus has not only been perceptually located in one or both ears, but patients have also indicated the presence of tinnitus in the middle, back, side or front of the head (Tyler \& Babin, 1993). The quality of the sound has frequently been described as buzzing or ringing, with other descriptions of rushing, roaring, whistling or pulsing also being indicated. Some patients have reported two or more sounds which may differ in pitch (Tyler \& Babin, 1993). High pitched tinnitus is more common (Tyler \& Babin, 1993), and when combined with relatively loud tinnitus tends to make the sound more annoying (Jakes, Hallam, Chambers \& Hinchcliffe, 1985; Tyler et al.,1992).

A number of surveys performed in the USA, the United Kingdom and Sweden have indicated that tinnitus is fairly common. Although there is a difference in the reported prevalence of tinnitus in each of the three countries, the results generally indicate that $6-20 \%$ of the population experiences tinnitus that can be bothersome, with $1 \%$ experiencing a severe tinnitus that interferes with daily activities (Chung, Gannon, \& Mason, 1984; Coles, 1987; Axelsson \& Ringdahl, 1989).

Tinnitus is not only a common condition, but often a debilitating one (Stouffer \& Tyler, 1990) as it may be "associated with considerable psychological distress such as anxiety, depression, irritability, and sleep disturbance" (Wilson, Henry, Bowen \& Haralambous, 1991:197). A number of studies have provided information on the psychosocial consequences of tinnitus. Difficulty falling asleep, trouble concentrating, feelings of anxiety, difficulty understanding speech, depression, annoyance, confusion, dependence on drugs, emotional distress, auditoryperceptual difficulties, and a deleterious effect on the ability to lead a normal life have been reported (Tyler \& Baker, 1983; Coles in Stouffer \& Tyler, 1990; Tyler, 1997a).

In order to investigate the experience of tinnitus from the patient's perspective, Stouffer and Tyler (1990) administered a questionnaire to 528 tinnitus sufferers who were representative of a clinic population. These researchers reported that the tinnitus population they studied did not necessarily present with a hearing loss. Perceptual characteristics of pitch and loudness were both rated as 7 on a Visual Analogue Scale of 1 to 10 by $65 \%$ and $47 \%$ of the subjects respectively. Patients whose primary complaint was tinnitus and those who were diagnosed as having Ménière's Disease reported the effects of tinnitus on daily life as more severe than those whose primary complaint was hearing loss. According to Stouffer and Tyler (1990), these results highlight the impact of tinnitus on people's lives. Therefore, by knowing how people perceive their tinnitus the clinician is better able to understand the problems that the tinnitus sufferer experiences and provide relevant information and intervention.

It is important to note that "each patient presents with his or her own personal responses to tinnitus" (Tyler, 1997a: 10). It has been noted that some people are not distressed by their tinnitus while others find it highly distressing (Dineen, Doyle \& Bench, 1997a). According to Tyler, Aran and Dauman (1992) two main factors contribute to the annoyance of tinnitus, namely, the tinnitus itself and psychological factors. The more unpleasant the quality of the tinnitus, the more annoying it is likely to be (Tyler et al., 1992) and the less people are able to cope with stressful situations, the more likely they are to be annoyed by the tinnitus (Tyler et al., 1992; Dineen et al., 1997a).

Axelsson and Ringdahl (1989) noted that some of the disturbing qualities of tinnitus are greater in the older population. Nevertheless, despite this finding, most studies appear to have targeted the general population of tinnitus patients, with few researchers focusing specifically on elderly persons. Aging involves molecular, cellular and organ changes that when combined, result in a decrease in the body's ability to respond to disruptions in homeostatic equilibrium (Chodzko-Zajko \& Ringel in Chodzko-Zajko, 1997). These "normal" changes can be accompanied by secondary or pathological problems which are often associated with aging (Lubinski \& Welland, 1997). Consequently, all elderly people undergo some degree of physical, mental and/or sensory function changes, yet not all are as successful as others in adapting to those changes (Lubinski \& Welland, 1997). The ability to adapt is usually influenced by the severity of the change, the ability of the person to access the internal assets accumulated throughout life, and the physical and social environmental resources available (Lubinski \& Welland, 1997).

Many older people are able to live their lives with considerable satisfaction and competence, with numerous surveys of life satisfaction demonstrating a general sense of well-being (Maddox, 1978). However, good health, adequate finances and someone to confide in, often play a role in determining a person's overall perception of their quality of life (Botwinick, 1984). This status is defined as "the degree of emotional, intellectual, or cultural satisfaction in one's everyday life, as distinct from the degree of material comfort" (Reader's Digest, 1984:1381). With regard to good health, it is not only the person's objective health status that plays a role, but literature studies have shown that older adults' feelings of life satisfaction can be influenced by their subjective health status (Spirduso \& GilliamMacRae, 1991). Both the severity and prevalence of tinnitus have been found to increase with age (Axelsson \& Ringdahl, 1989). Tinnitus can therefore play a role in elderly people's subjective perception of their health status. In addition, if they perceive tinnitus as a threat to their health, their quality of life could be affected.

Although there appears to be little, if any, research in the area of tinnitus currently being conducted in South Africa, according to statistics of the prevalence of tinnitus in the USA, the UK and Sweden, namely 6\%-20\%, it seems reasonable to assume that a relatively large number of people in South Africa probably suffer from this disorder. It would therefore seem important to highlight the presence and impact of tinnitus on people's quality of life so that intervention can be provided to decrease the level of distress and annoyance associated with this condition (Dineen, Doyle \& Bench, 1997b).

Many of the studies on the psychosocial aspects of tinnitus have used the University of Iowa Tinnitus Questionnaire developed by Stouffer and Tyler (1990) or various tinnitus handicap scales (e.g., Tyler \& Baker, 1983; Hallam, Jakes \& Hinchcliffe, 1988; Kuk, Tyler, Russel \& Jordan, 1990). However, most of these research instruments were designed for the general population of tinnitus sufferers and do not specifically target elderly persons. For example, the Tinnitus Questionnaire includes items not necessarily applicable to senior citizens, such as questions regarding menstruation, shooting guns, rifles and so forth. This particular research tool also presupposes 
a fairly sophisticated target group which is able to quantify percentage of time that tinnitus is present on a scale from 1 to 100 . For this reason, the present study endeavoured to adapt the University of Iowa Tinnitus Questionnaire (Stouffer \& Tyler, 1990) and the Tinnitus Reaction Questionnaire (Wilson et al., 1991) to meet the needs of a group of senior citizens.

The present study also falls within the framework of current health and welfare policy in this country. For example, the White Paper for the Transformation of the Health System in South Africa (1997:13) states that the "emphasis should be placed on reaching the poor, the under-served, the aged, women and children who are amongst the most vulnerable". The White Paper for Social Welfare (1997:71) refers to older persons and states that "there needs to be a good balance between an emphasis on duration of life and quality of life". The effects of tinnitus need to be researched in the elderly population because this condition has the potential of adversely affecting quality of life (Tyler \& Babin, 1993).

\section{METHODOLOGY}

\section{$\boldsymbol{A I M}$}

The overall aim of the study was to investigate the perceptions of tinnitus in a group of senior citizens.

\section{Sub-aims}

(1) To assess respondents' perceptions of the auditory characteristics of tinnitus.

(2) To determine the effect of tinnitus on quality of life.

(3) To elicit information on the respondents' perceptions of the cause/s of their tinnitus.

(4) To highlight factors perceived to aggravate or ameliorate the experience of tinnitus.

(5) To explore the coping strategies employed.

\section{RESEARCH DESIGN}

In order to investigate the aims of the study, a survey design which involved the administration of a questionnaire was used. The purpose of this design was "to provide a detailed inspection of the prevalence of conditions, practices, or attitudes in a given environment by asking people about them rather than observing them directly" (Ventry \& Schiavetti, 1980:52).

\section{SUBJECTS}

A sample size of 20 persons presenting with tinnitus was used. Subjects were recruited from three Old-Age Homes in the Gauteng area, using nonprobability snowball sampling techniques (Baker, 1988).

\section{Subject Selection Criteria}

(1) Subjects were required to suffer from any type of tinnitus, as this was the phenomenon under investigation.

(2) Subjects needed to be 60 years of age or older, thereby falling into the category of senior citizen in which there is a higher prevalence of tinnitus (Axelsson \& Ringdahl, 1989).
(3) Subjects had to have no diagnosed psychiatric illness in which the person might experience auditory hallucinations, which could be confused with tinnitus, thus confounding the results (Jackson, 1983:159).

(4) Subjects needed to have the cognitive-linguistic ability to understand and answer the questionnaire. (Information on (3) and (4) was obtained from the health care personnel at the various old-age homes.)

\section{Description of subjects}

The occurrence of tinnitus in relation to age, gender, previous occupation, hearing loss, primary diagnosis and primary complaint is set out in Table 1.

\section{RESEARCH INSTRUMENTATION}

A tinnitus questionnaire based on an adaptation of The University of Iowa Tinnitus Questionnaire (Stouffer \& Tyler, 1990) and the Tinnitus Reaction Questionnaire (Wilson et al., 1991) was used to quantify the data. These two research instruments were chosen because they covered areas targetted in the present study. The questionnaire is set out in Appendix A, and comprised the following sections:

\section{Covering letter}

A covering letter not included with the original research tools, provided subjects with a brief explanation of the purpose and usefulness of the research, what the session would entail, as well as an assurance of confidentiality and voluntary participation.

\section{Biographical information}

Subjects were required to provide details regarding their age, previous occupation and gender. Previous occupation was important since patients exposed to occupational noise have a $70 \%$ risk of tinnitus (Coles in Stouffer \& Tyler, 1990). Information on age was sought because within the population over 50 years of age approximately $40 \%$ have tinnitus (Axelsson \& Ringdahl, 1989). This increase in prevalence with age is possibly due to the increase in hearing loss and accumulated noise exposure, both of which are implicated in sensorineural tinnitus (Chung et al., 1984; Tyler, 1997a).

\section{Perceptual characteristics}

This section was designed to gather information from respondents on the perceived location, sound quality, pitch and loudness of their tinnitus, as well as time since onset and how often the tinnitus bothered them. Stouffer and Tyler (1990) and Tyler and Babin (1993) have highlighted the importance of quantifying these perceptual characteristics of tinnitus.

\section{Psychosocial effects}

The aim of this section was to determine the effects of tinnitus on the person's lifestyle, emotions and general health. Information was elicited in order to highlight the presence and impact of tinnitus on people's quality of life so that relevant intervention could be provided to decrease the level of distress and annoyance associated with it. 


\section{Etiology}

The rationale for including this section, was that an understanding of the possible causes of tinnitus could possibly serve to reduce the effects of the condition by eliminating the cause (Stouffer \& Tyler, 1990).

\section{Factors influencing tinnitus}

This section was designed to highlight factors that exacerbate or reduce a person's tinnitus. Such information was felt to be useful in planning management strategies for tinnitus patients (O'Connor \& Zappia, 1993).

\section{Coping strategies}

This question explored how people coped with their tinnitus. It has been found that a person's ability to cope may influence the amount of distress associated with tinnitus (Lindberg, Scott, Melin \& Lyttkens, 1987).

\section{Additional comments}

Additional views were targeted through an open-ended question which was placed toward the end of the questionnaire (de Vaus, 1991) allowing respondents to elaborate on their general feelings and experience of tinnitus (Singleton, Straits \& Straits, 1993).

\section{Audiological characteristics}

Based on a similar section in Stouffer and Tyler's (1990) study, this section, filled in by the audiologist, provided information on the subjects' primary diagnosis, primary complaint and hearing thresholds at 1000 and $4000 \mathrm{~Hz}$. Since tinnitus and hearing loss usually co-exist (Tyler, 1997a) this information was included to illustrate the relationship between the tinnitus and hearing loss, particularly presbycusis in the elderly population.

\section{PRE-TEST OF THE RESEARCH INSTRUMENT}

The tinnitus questionnaire adapted from The University of Iowa Tinnitus Questionnaire (Stouffer \& Tyler, 1990) and the Tinnitus Reaction Questionnaire (Wilson, et al., 1991) was used in the pre-test on two subjects who were not included in the final study. On the basis of the pilot study the questionnaire was further adapted for senior citizens. Namely, a larger font size was used to facilitate reading, and various questions were removed or modified. Firstly, the questions requiring the percentage of time tinnitus was present and the number of days per month that tinnitus was bothersome were deleted. They were replaced with an open-ended question on how often tinnitus bothered the subject. This item was placed in the biographical details section. The questions targeting the effects of tinnitus on respondents' quality of life were changed from a percentage scale ranging from 1-100 (Stouffer \& Tyler, 1990) to a four-point scale where $1=$ never, $2=0$ ccasionally, $3=$ often, $4=$ all the time. The question on causation of tinnitus was modified from a choice of possible causes to an open-ended question as the pretest subjects circled a possible cause and the "I have no idea" item where only one answer was required. The

TABLE 1: Description of subjects $(\mathrm{N}=\mathbf{2 0})$

\begin{tabular}{|c|c|c|c|}
\hline Demographic factor & Sample & No. & Percentage \\
\hline 1. Age & $\begin{array}{l}60-69 \\
70-79 \\
80-89 \\
90-99\end{array}$ & $\begin{array}{c}6 \\
10 \\
3 \\
1\end{array}$ & $\begin{array}{c}30 \\
50 \\
15 \\
5\end{array}$ \\
\hline 2. Gender & $\begin{array}{l}\text { Female } \\
\text { Male }\end{array}$ & $\begin{array}{c}12 \\
8 \\
\end{array}$ & $\begin{array}{l}60 \\
40 \\
\end{array}$ \\
\hline $\begin{array}{l}\text { Previous } \\
\text { occupation }\end{array}$ & $\begin{array}{l}\text { Home (quiet) } \\
\text { Office (Semi-quiet) } \\
\text { Other (semi-noise) } \\
\text { Factory (noise) }\end{array}$ & $\begin{array}{l}3 \\
8 \\
6 \\
3\end{array}$ & $\begin{array}{l}15 \\
40 \\
30 \\
15\end{array}$ \\
\hline $\begin{array}{l}\text { 4. Hearing loss } \\
\text { (left ear) }\end{array}$ & $\begin{array}{l}\text { slight }(16-25 \mathrm{~dB}) \\
\text { mild }(26-40 \mathrm{~dB}) \\
\text { moderate }(41-65 \mathrm{~dB}) \\
\text { severe }(66-95 \mathrm{~dB})\end{array}$ & $\begin{array}{c}1 \\
4 \\
11 \\
4 \\
\end{array}$ & $\begin{array}{c}5 \\
20 \\
55 \\
20 \\
\end{array}$ \\
\hline 5. Hearing loss & $\begin{array}{l}\text { slight }(16-25 \mathrm{~dB}) \\
\text { mild }(26-40 \mathrm{~dB}) \\
\text { moderate }(41-65 \mathrm{~dB}) \\
\text { severe }(66-95 \mathrm{~dB})\end{array}$ & $\begin{array}{c}3 \\
5 \\
10 \\
2\end{array}$ & $\begin{array}{l}15 \\
15 \\
50 \\
10\end{array}$ \\
\hline 6. Primary diagnosis & $\begin{array}{l}\text { Noise-induced loss } \\
\text { Presbycusis } \\
\text { Middle ear disorder } \\
\text { Normal hearing } \\
\text { Other }\end{array}$ & $\begin{array}{c}4 \\
12 \\
1 \\
2 \\
1\end{array}$ & $\begin{array}{c}20 \\
60 \\
5 \\
10 \\
5 \\
\end{array}$ \\
\hline 7. Primary complaint & $\begin{array}{l}\text { Hearing loss } \\
\text { Tinnitus }\end{array}$ & $\begin{array}{c}11 \\
9\end{array}$ & $\begin{array}{l}55 \\
45\end{array}$ \\
\hline
\end{tabular}


item referring to "shooting guns, rifles" as well as the item on menstruation in the list of factors that make tinnitus worse, were removed as they were deemed irrelevant for the elderly population. The subjects used in the pilot study were not included in the final administration of the questionnaire.

\section{ADMINISTRATION OF THE QUESTIONNAIRE}

The Tinnitus Questionnaire was administered individually to subjects in order to provide assistance or clarification where necessary, as opposed to a postal survey in which such assistance would not have been possible. While some subjects completed the questionnaire on their own, others requested the researchers' help in this regard because they had, for example, not brought with their reading glasses. The speech therapist at the one Old-Age Home liaised between the researcher and patients and accessed the relevant audiological information set out in Section H of the Tinnitus Questionnaire. Since no audiological information was available for the subjects from the other two Homes, a screening audiometer was used by the researcher to obtain the hearing thresholds at 1000 and $4000 \mathrm{~Hz}$ as recommended by Stouffer and Tyler (1990).

\section{DATA ANALYSIS}

The results were analysed using descriptive statistics, in which quantitative information or data are organized, summarized and described (McCall, 1994). Content analysis was used to analyze qualitative data from the openended questions according to themes articulated by respondents (Dooley, 1995).

\section{RESULTS AND DISCUSSION}

The following results are discussed in accordance with the sub-aims of the study.

\section{AUDITORY-PERCEPTUAL CHARACTERISTICS}

The auditory-perceptual characteristics of place, quality, pitch, loudness, time since onset and how often respondents were bothered by tinnitus are set out in Table 2 .

TABLE 2: Description of auditory-perceptual characteristics of tinnitus ( $N=20)$

\begin{tabular}{|c|c|c|c|}
\hline Tinnitus characteristic & Sample & No. & Percentage \\
\hline 1. Place & $\begin{array}{l}\text { Left ear } \\
\text { Right ear } \\
\text { Both ears equally } \\
\text { Both, left worse } \\
\text { Both, right worse } \\
\text { Head } \\
\text { Head, right }\end{array}$ & $\begin{array}{l}6 \\
2 \\
4 \\
2 \\
1 \\
4 \\
1\end{array}$ & $\begin{array}{r}30 \\
10 \\
20 \\
10 \\
5 \\
20 \\
5\end{array}$ \\
\hline 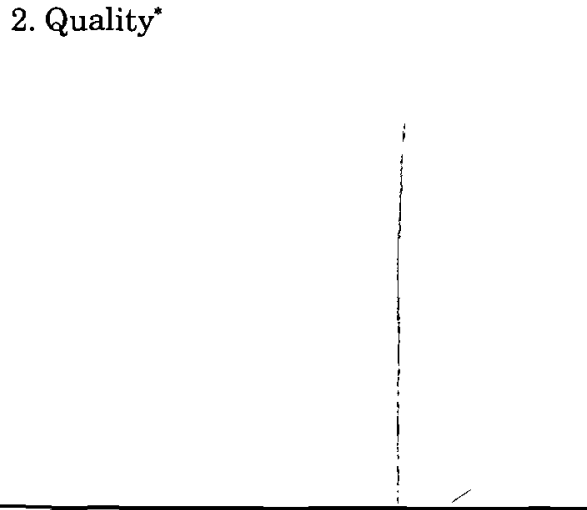 & $\begin{array}{l}\text { buzzing } \\
\text { hissing } \\
\text { humming } \\
\text { ringing } \\
\text { other } \\
\text { cricket-like } \\
\text { whistling } \\
\text { clicking } \\
\text { crackling } \\
\text { popping } \\
\text { roaring } \\
\text { steam whistle } \\
\text { whooshing }\end{array}$ & $\begin{array}{r}10 \\
7 \\
6 \\
4 \\
3 \\
3 \\
2 \\
2 \\
1 \\
1 \\
1 \\
1 \\
1\end{array}$ & $\begin{array}{r}23,8 \\
16,7 \\
14,2 \\
9,5 \\
7,1 \\
7,1 \\
4,8 \\
4,8 \\
2,4 \\
2,4 \\
2,4 \\
2,4 \\
2,4\end{array}$ \\
\hline 3. Pitch & $\begin{array}{l}\text { mean } \\
\text { median } \\
\text { range }\end{array}$ & $\begin{array}{l}5,3 \\
5,7 \\
1-8\end{array}$ & $\begin{array}{l}- \\
- \\
\end{array}$ \\
\hline 4. Loudness & $\begin{array}{l}\text { - mean } \\
\text { - median } \\
\text { - range }\end{array}$ & $\begin{array}{c}5,7 \\
5,9 \\
1-10\end{array}$ & $\begin{array}{l}- \\
-\end{array}$ \\
\hline 5. Time in years since onset of tinnitus & $\begin{array}{ll}\text { - } & 0-8 \\
\text { - } & 9-16 \\
\text { - } & 17-24 \\
\text { - } & 25-32 \\
\text { - } & 33-40 \\
\end{array}$ & $\begin{array}{r}10 \\
1 \\
3 \\
4 \\
2 \\
\end{array}$ & $\begin{array}{r}50 \\
5 \\
15 \\
20 \\
10 \\
\end{array}$ \\
\hline 6. How often tinnitus bothered them & $\begin{array}{l}\text { - } \text { sometimes } \\
\text { - often } \\
\text { - all the time }\end{array}$ & $\begin{array}{l}9 \\
6 \\
5\end{array}$ & $\begin{array}{l}45 \\
30 \\
25\end{array}$ \\
\hline
\end{tabular}

\footnotetext{
* Responses regarding quality do not add up to 20 as respondents reported more than one type of sound.
} 
The responses indicated that the perceptual location of tinnitus could be in either ear (40\%), both ears (35\%) or in the head (25\%) This phenomenon has been found by numerous other researchers (Miekle \& Griest, 1987; Axelsson \& Ringdahl, 1989; Stouffer \& Tyler, 1990), all of whom have found a higher incidence of bilateral tinnitus as opposed to a unilateral location. In addition, a quarter of the respondents reporting unilateral tinnitus were male and three-quarters were female which reflects the apparent prevalence of unilateral tinnitus in females (Erlandsson, Hallberg \& Axelsson, 1992) and bilateral in males (Axelsson \& Ringdahl, 1989). The present finding of a higher prevalence of left ear tinnitus (30\%) corresponds with previous studies (Lindberg et al., 1984; Axelsson \& Ringdahl, 1989; Stouffer \& Tyler, 1990). Numerous hypotheses have been suggested, namely handedness, asymmetric noise exposure, the predominance of left-sided vascular disease and the physiological asymmetry of the lower brainstem in humans (Hallam, Rachman \& Hinchcliffe, 1984; Stouffer \& Tyler, 1990).

According to Axelsson and Ringdahl (1989), a reason for the difference in laterality could be due to left-sided noiseinduced hearing loss being more common than right-sided. Since unilateral tinnitus is more likely to be in the ear with greater hearing loss (Chung et al., 1984) left-sided tinnitus should be more common. This situation is reflected by the present findings in which $75 \%$ of respondents presented with a moderate to severe loss in the left ear, compared to $60 \%$ in the right ear. Yet, in Chung, Gannon and Mason's (1984) study no lateral difference in the prevalence of tinnitus was found. However, Tyler and Babin (1993) caution that the perceptual location may be misleading and is of limited diagnostic importance.

Most of the subjects provided more than one response item for the quality of the tinnitus with the three most common responses being buzzing (24\%), hissing (17\%) and humming (14\%). These are different when compared to Stouffer and Tyler's (1990) finding of ringing (38\%), buzzing $(11 \%)$, cricket-like sounds (9\%) and hissing (8\%). However, the ordering effect, with buzzing appearing first on the list, may have influenced the choice of response. In addition, these descriptions are dependent on the vocabulary of the respondent and their previous listening experience and therefore have limited diagnostic significance (Tyler \&

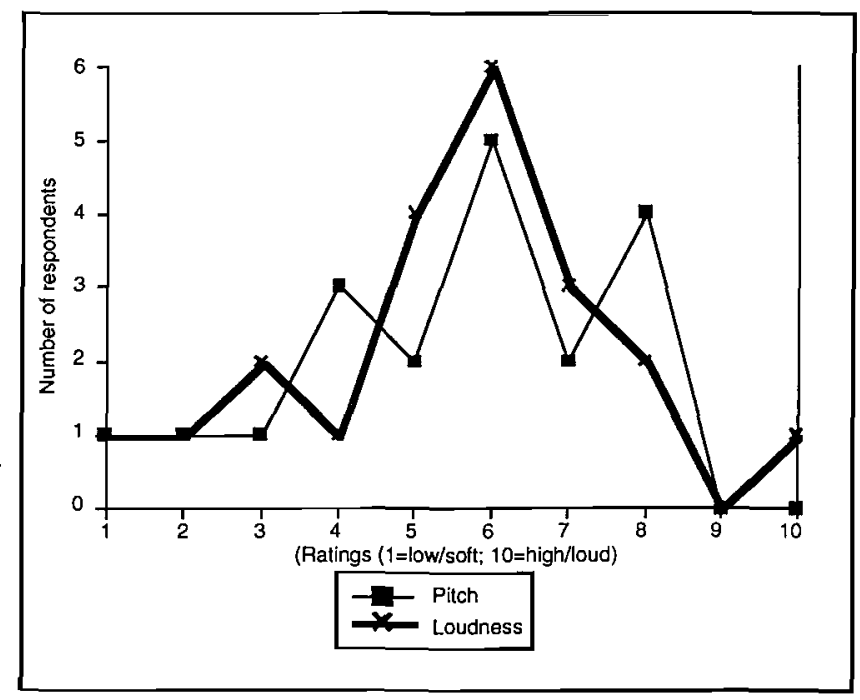

FIGURE 1. Subjective ratings of pitch and loudness of tinnitus $(\mathbf{N}=\mathbf{2 0})$
Babin, 1993). However, reports of pulsing or popping sounds, although they may occur in sensorineural tinnitus, should alert the physician or clinician to the presence of muscular or vascular tinnitus (Tyler \& Babin, 1993).

Results in respect of respondents' perceptions of the pitch and loudness of their tinnitus are illustrated in Figure 1.

Respondents rated the relative pitch of their tinnitus on a subjective Visual Analogue Scale ranging from 1 to 10 where 1 was very low and 10 very high. The mean pitch rating was $5,3(\mathrm{SD}=1,9)$ with a range of 1 to 8 . It was observed that $50 \%$ of the respondents rated their pitch in a mid-range position of 5 and 6 , with no difference between those reporting a higher pitch rating of 7 and above (25\%) and those with a lower rating of 4 and less (25\%). This finding is in contrast to previous observations that most tinnitus sufferers report a high-pitched tinnitus (Stouffer \& Tyler, 1990) frequently matching their tinnitus at frequencies around or above 2000,3000 and $4000 \mathrm{~Hz}$ (Tyler $\&$ Babin, 1993). However, many of the respondents in this study stated that they had difficulty rating their pitch as it varied and were unsure of what constituted a low or high pitch. This result is consistent with Stouffer and Tyler's (1990) finding that tinnitus pitch could vary daily. As a result, pitch matching reliability varies among patients (Tyler \& Babin, 1993: 3037). Although individuals do differ in regard to their perception of high and low pitch, which tends to make it difficult to compare values between subjects, scaled values have been found to be reliable within subjects (Hellman \& Meiselman, 1988).

Loudness was rated on a similar scale resulting in a mean loudness rating of $5,7(\mathrm{SD}=2,25)$ and a range of $1-10$. It was observed that $35 \%$ of the respondents rated their loudness in a mid-range position of 5 and 6 , with the same number, namely $35 \%$, reporting a higher loudness rating of 7 and above, while $30 \%$ recorded a lower rating of 4 and less. Some patients indicated that the loudness of their tinnitus changed. This finding was also reported by Stouffer and Tyler (1990) with more than $50 \%$ of their respondents experiencing fluctuations in tinnitus loudness. It has been generally found that most patients match the loudness of their tinnitus to a few decibels above their hearing threshold (Lindberg, Lyttkens, Melin \& Scott, 1984). However, Tyler and Babin (1993) point out that this sensation level is an intensity measure and not a measurement of loudness (sones). Therefore, with hearing threshold and loudness recruitment taken into account, an increase in hearing threshold could result in tinnitus being perceived as exceptionally loud (Tyler \& Babin, 1993).

A slight difference in pitch and loudness ratings between males and females was observed. For males the mean pitch rating was 5,8 (range $=2-8$ ) and loudness 6,4 (range $=4$ $10)$, with females giving a mean rating of 4,9 (range $=1-8$ ) for pitch and 5,1 (range =1-8) for loudness. These results do not reflect Dineen, Doyle and Bench's (1997a) finding that female subjects perceived their tinnitus as louder and more annoying than their male counterparts.

For $50 \%$ of respondents, tinnitus onset was within the past 8 years. In relation to Stouffer and Tyler's (1990) result of $62 \%, 45 \%$ of the respondents in the present study reported the onset of tinnitus within the previous 5 years and $10 \%$ as opposed to $18 \%$ within the previous $6-10$ years. Although a fairly similar trend was noted between the two studies with a large percentage of respondents reporting a recent time since onset, the present study demonstrated a larger mean time since onset of 13,5 years $(\mathrm{SD}=13,4)$ as opposed 
to Stouffer and Tyler's (1990) mean of 7,6 years ( $\mathrm{SD}=9,9)$. This finding may have been related to the fact that the study targeted senior citizens who had probably suffered from tinnitus for longer periods of time than members of the general population.

The mean age for the onset of tinnitus was 58,4 years $(\mathrm{SD}=16,6)$ thus falling into the most common period for the onset of tinnitus, namely middle age (i.e., 50 to 60 years). This finding can be explained by the reduced metabolic responsiveness of the auditory system associated with aging resulting in increased sensitivity to noise and drug stress (Miller, Dolan, Raphael, Altschuler, 1998). However, a range of 25 to 85 years was present in the sample.

It was found that $45 \%$ of the respondents were only bothered by their tinnitus some of the time, while $25 \%$ were bothered all the time. The remaining 30\% experienced difficulty answering this question because of the variable nature of their tinnitus. Moreover, due to the somewhat ambiguous wording of the question, it cannot be determined whether the time respondents were bothered by tinnitus corresponded to the time it was present or only to a part of that time when they were bothered by their tinnitus. Assuming that the information obtained was an indication of time tinnitus was present, on the basis that respondents' tinnitus was variable, then this result does not correspond with Stouffer \& Tyler's (1990) finding that $68 \%$ of their respondents indicated that their tinnitus was present for more than $80 \%$ of the time. Nonetheless, the variability of tinnitus did not necessarily reduce the annoyance produced by the condition but, as explained by one respondent, was more irritating because it would come on suddenly. Since tinnitus is a chronic condition, there is no direct relationship between the amount of impairment and the disabling and handicapping effects of tinnitus (Hallam et al., 1984).

In summary, although the findings regarding the auditory-perceptual characteristics do not necessarily aid in diagnosing causation of tinnitus, they are nevertheless important in that they enhance audiologists' understanding of the condition from the client's perspective. In addition, such subjective descriptions i of tinnitus should provide useful information that could aid in the design of therapeutic programmes (Stouffer \& Tyler, 1990). According to Tyler, Stouffer and Schum (1989), discussing the problems tinnitus patients generally experience and the difficulties they tend to encounter in describing the sounds they hear, can be a helpful and therapeutic strategy in counselling individual tinnitus clients and their families.

\section{EFFECTS OF TINNITUS ON QUALITY OF LIFE}

Approximately a third, namely $35 \%$, of respondents indicated that their overall enjoyment of life was affected by their tinnitus. Table 3 demonstrates the frequency with which tinnitus affected their quality of life.

It was noted that respondents were most affected in noisy situations $(65 \%)$, in relation to their capacity to relax $(65 \%)$, in their ability to follow a conversation (55\%) and in their ability to concentrate $(50 \%)$. One respondent provided further information on how her quality of life was affected by stating that she would no longer listen to music because she feared it would trigger her tinnitus. The weighted scores did not alter the rank order of the life functions/situations according to the percentage of respondents that were affected. Instead the weighted scores served to distinguish between life function categories those with the same percentage of respondents. For example, $65 \%$ of respondents were affected by noisy situations and experienced difficulty relaxing, yet tinnitus was shown to affect noisy situations more often than the ability to relax as demonstrated by the weighted score of 23 as compared to 18 . However, it is not known whether tinnitus was the only cause of the difficulties experienced in noise and the ability to follow a conversation since all of the respondents presented with co-occurring hearing losses.

Previous studies commonly report difficulties in sleep and ability to concentrate (Tyler \& Baker, 1983; Jakes et al., 1985; Slater \& Terry, 1987; Axelsson \& Ringdahl, 1989; Stouffer \& Tyler, 1990). Moreover, it has been reported that females are more likely than males to report difficulty falling asleep (Stouffer \& Tyler, 1990; Dineen et al., 1997a).

TABLE 3: Frequency with which tinnitus affected various life functions/situations $(\mathrm{N}=20)$

\begin{tabular}{|l|c|c|c|}
\hline Life functions/situations & No. & Weighted score* & Percentage \\
\hline Avoid noisy situations & 13 & 23 & 65 \\
Ability to relax & 13 & 18 & 65 \\
Difficulty following a conversation & 11 & 18 & 55 \\
Ability to concentrate & 10 & 14 & 50 \\
Difficulty understanding speech & 9 & 13 & 45 \\
Caused tiredness & 8 & 12 & 40 \\
Enjoyment of life & 7 & 11 & 35 \\
Difficulty with sleep & 7 & 9 & 35 \\
Avoid social situations & 5 & 8 & 25 \\
Avoid quiet situations & 5 & 6 & 25 \\
Ability to work & 3 & 5 & 15 \\
Interferes with relationships & 3 & 4 & 15 \\
\hline
\end{tabular}

* Weighted scores were obtained by arbitrarily assigning the value of 1 to the response of 'sometimes', 2 to 'often'and 3 to 'all the time'. Each value was multiplied by the number of responses, respectively. The sub-totals were combined to form the weighted score. 
However, this finding was not obtained in the present study with $35 \%$ of respondents, $43 \%$ of whom were female and $57 \%$ male, reporting occasional interference with sleep. Furthermore, Axelsson and Ringdahl (1989) found a significant relationship between the severity of tinnitus and difficulties in falling asleep. Even if the amount of time that tinnitus is bothersome is regarded as an index of the severity of tinnitus it was still found that sleep was not disturbed in $64 \%$ of those respondents bothered by their tinnitus often or all the time. Nevertheless, of the 7 respondents indicating loud tinnitus (rating of 7 or more) $43 \%$ indicated that tinnitus interfered to some degree with sleep. Slater and Terry (1987) found that tinnitus loudness and difficulty getting to sleep were significantly associated. However, although sleep is affected in some tinnitus patients, Coles (in Slater \& Terry, 1987) cautions that some individuals with severe tinnitus may not experience sleep difficulties. Therefore sleep disturbance cannot be used as a clinical indicator of tinnitus severity.

Table 4 shows that $70 \%$ of respondents reported that their tinnitus caused them to be frustrated, $60 \%$ felt that it made them feel tense, $55 \%$ stated that the condition caused feelings of irritability and $50 \%$ reported depression. Although more respondents, namely $45 \%$, indicated that their tinnitus caused them to be confused compared to $40 \%$ reporting that the condition made them unhappy, unhappiness due to tinnitus occurred more frequently as indicated by the slightly stronger weighting of 11 .

Depression, anxiety and annoyance have been highlighted as the common emotional reactions to tinnitus in previous studies (Tyler \& Baker, 1983; Tyler, 1997a; Scott, Lindberg, Melin \& Lyttkens, 1990; Stouffer \& Tylè, 1990;). This finding could simply be due to differences in terminology as, for example, Tyler and Baker (1983) combined despair, frustration and depression as one difficulty experienced by tinnitus patients, whereas the Tinnitus Reaction Questionnaire (Wilson et al., 1991), on which the present study's questionnaire was based, lists frustration and depression as separate entities. In addition, each tinnitus patient presents with his or her own responses to tinnitus, therefore, patients with similar descriptions of tinnitus may react very differently (Tyler, 1997a). In the present study two respondents indicated that, in terms of the possible reactions listed, they were not affected by their tinnitus. For example, one respondent stated that she did not panic but simply took things as they came. Tyler and Baker (1983) comment that many tinnitus patients have only a few problems associated with their tinnitus, and either are not sufficiently troubled by it or have adjusted their lifestyle in order to cope. Slater and Terry (1987) explain this finding in terms of personality type, in which introverted individuals are more likely to be aware of their tinnitus and so be annoyed by it. Nevertheless, the results also clearly indicate that tinnitus did affect the group of respondents surveyed, as seen by one person's comment that it was "highly irritating". One subject mentioned that the tinnitus would get so bad that it would drive her frantic. She explained that if it had not been for her children she would have thrown herself off the balcony of her flat on the third floor. Another respondent who was boarded because of his tinnitus, stated "I am permanently on an antidepressant and intermittently on tranquilizers". Scott, Lindberg, Melin and Lyttkens (1990) found that tinnitus creates greater levels of insomnia, depression, anxiety and difficulties with concentration in tinnitus patients compared to patients with a hearing loss only. Therefore, whether tinnitus is the sole cause of these reactions or certain individuals are predisposed to them, tinnitus does appear to result in diverse reactions, many of which cause serious problems for the patient (Tyler \& Baker, 1983).

In terms of the effects of tinnitus on general health, $23 \%$ of respondents indicated that tinnitus caused them to feel dizzy, while $19 \%$ reported losing their balance. The prevalence of balance problems, tinnitus and hearing

TABLE 4: Frequency with which emotional responses to tinnitus were experienced(N=20)

\begin{tabular}{|c|c|c|c|}
\hline Emotional responses & No. & Weighted score* & Percentage \\
\hline Frustrated & 14 & 20 & 70 \\
\hline Tense & 12 & 17 & 60 \\
\hline Irritable & 11 & 13 & 55 \\
\hline Depressed & 10 & 13 & 50 \\
\hline Confused & 9 & 10 & 45 \\
\hline Unhappy & 8 & 11 & $40_{!}^{\prime}$ \\
\hline Annoyed & 7 & 9 & 35 \\
\hline Tormented & 5 & 7 & 25 \\
\hline Driven crazy & 5 & 7 & 25 \\
\hline Angry & 5 & 6 & 25 \\
\hline Helpless & 5 & 6 & 25 \\
\hline Hopeless & 4 & 6 & 20 \\
\hline Tearful & 2 & 3 & 10 \\
\hline Contemplated suicide & 2 & 3 & 10 \\
\hline
\end{tabular}

* Weighted scores were obtained by arbitrarily assigning the value of 1 to the response of 'sometimes', 2 to 'often' and 3 to 'all the time'. Each value was multiplied by the number of responses, respectively. The sub-totals were combined to form the weighted score. 
threshold generally increase with an increase in age (Chung et al., 1984; Shepard \& Telian, 1994). It is likely that, just as tinnitus is a symptom of auditory dysfunction (Tyler, 1997a), balance difficulties along with tinnitus and a hearing loss indicate an underlying auditory system problem. For example, patients with Menière's disease present with symptoms of vertigo, low frequency hearing loss and roaring tinnitus (Slater \& Terry, 1987). Tyler and Baker (1983) reported that $13,8 \%$ of their respondents experienced giddiness, balance or 'fuzzy head' problems. In addition, $40 \%$ of the respondents (making up $22 \%$ of the responses) indicated concern that tinnitus might cause them to become deaf. Previous research has shown a range from $5 \%$ (Slater \& Terry, 1987) to $55 \%$ of respondents (Stouffer \& Tyler, 1990) expressing this concern.

Findings from the present study highlight the need for clinicians to adopt a holistic approach to the assessment and treatment of tinnitus. Besides helping patients cope with the consequences of tinnitus on their daily lives, their families need to be involved in the management of tinnitus, as they are also indirectly affected (Tyler \& Babin, 1993:3031).

\section{PERCEIVED CAUSES OF TINNITUS}

An open-ended question was used to elicit respondents' perceptions of the cause of their tinnitus. A summary of the general themes articulated are presented in Table 5.

Respondents provided a variety of explanations for the cause of their tinnitus. One couple explained that while in a neighbouring country, they and a few other South Africans suddenly developed tinnitus. The husband felt that this outcome was due to the high pitched hum produced by his TV screen once it was programmed to receive the Zimbabwean television signal. Two people felt that syringing was implicated. The one respondent explained that he had a problem with his ears in which wax formed, causing his ears to clog up so they had to be syringed every year. He was convinced that the nozzle of the syringe actually penetrated the ear drum, and reasoned that his tinnitus would get better as the ear drum healed. The literature does report that some patients have indicated that ear syringing has been a precipitating factor in the onset of tinnitus (Slater \& Terry, 1987). One lady was under the impression that too much salt in her diet caused her tinnitus. Although no systematic research appears to have been performed to determine the effects of food on tinnitus,
Slater and Terry (1987) provide anecdotal evidence that dietary factors do play a role for some individuals. The largest proportion of respondents did not know what had caused their tinnitus. This finding of $40 \%$ was similar to $46 \%$ of respondents in Stouffer and Tyler's (1990) study who also had no idea what had caused the condition. One man in the present study mentioned that prior to being referred by the speech therapist to the researcher, he had not known that the condition he suffered from was called tinnitus, and was unaware of the cause of his tinnitus.

Middle ear tinnitus can be of vascular or muscular origin (Slater \& Terry, 1987; Stouffer \& Tyler, 1990; Tyler \& Babin, 1993) resulting from vascular tumours or developmental arteriovenous malformations in the ear or head region, or muscle spasms of the palatal or middle ear muscles (Tyler \& Babin, 1993). It is hypothesised that sensorineural tinnitus involves hyperactive hair cells or nerve fibres, or decoupling of hair cell steriocilia, due to damage to the auditory system (Slater \& Terry, 1987; Stouffer \& Tyler, 1990; Tyler, 1997a). Various causes are implicated, namely, Menière's Disease, acoustic trauma, long-term noise exposure, aging, ototoxic drugs and certain diseases (Slater $\&$ Terry, 1987). However, the causes of tinnitus are largely unknown (Tyler, 1997a).

The implication of the findings from the present study, is that audiologists need to be involved in campaigns to create public awareness of tinnitus. Audiologists also need to share their knowledge about tinnitus during counselling sessions with patients. This kind of information usually helps clients to realize that the audiologist recognises that their tinnitus is a real phenomenon and not merely an imaginary ailment. Moreover, in cases of middle-ear tinnitus it is important for audiologists to make medical referrals in order to determine if medically- or surgicallytreatable diseases, namely glomus tumours, arteriovenous malformations, Menière's disease and acoustic tumours, are present (Stouffer \& Tyler, 1990).

\section{FACTORS AFFECTING TINNITUS}

Table 6 lists the factors perceived by respondents to aggravate their experience of tinnitus.

Being in a noisy place and mental/emotional stress were each identified by $45 \%$ of the respondents as being the main factors exacerbating their tinnitus. These two factors were also highly implicated in Stouffer and Tyler's (1990) study, with $31 \%$ and $29 \%$ of respondents indicating that

\section{TABLE 5: Perceived causes of tinnitus $(\mathrm{N}=20)$}

\begin{tabular}{|l|l|c|c|c|}
\hline Cause & Sub-Cause & Responses & Percentage & Total \\
\hline No idea & & 8 & 40 & 40 \\
\hline Noise-related & - General & 2 & 10 & 30 \\
& - Work & 2 & 10 & \\
& - Af & 2 & 10 & \\
\hline \multirow{2}{*}{ Ear-related football } & - Infection & 1 & 5 & 25 \\
& - Syringe & 2 & 10 & \\
\hline Other & Deaf & 1 & 5 & 5 \\
\hline
\end{tabular}


their tinnitus was made worse by being in a noisy place and emotional/mental stress respectively. However, their results showed that the primary situation that exacerbated tinnitus for $36 \%$ of respondents was being in a quiet place (Stouffer \& Tyler,1990). Many of the respondents in the present study mentioned that quiet situations made them more aware of their tinnitus but did not necessarily make it worse. Slater and Terry (1987) reported that $28 \%$ and $27 \%$ of respondents indicated that loud noises exacerbated tinnitus when they were present and when they had ceased respectively. Fifteen percent of respondents in the present study indicated that drugs or medicine served to worsen tinnitus. This result is supported by findings in the literature that several antibiotics, especially the mycins, aspirin and anti-depressants are known to produce or exacerbate tinnitus (Slater \& Terry, 1987). Other nonmedically related factors that served to exacerbate tinnitus, namely caffeine, alcohol and nicotine, were each implicated by $5 \%$ of respondents. Although the exact mechanisms of how tinnitus is influenced by these substances is not fully understood, anecdotal evidence (Slater \& Terry, 1987) supports the finding that caffeine, alcohol and nicotine do make tinnitus worse for some individuals.

Table 7 lists the factors that reduce tinnitus severity.

For $45 \%$ of respondents nothing reduced their tinnitus. This figure is consistent with Stouffer and Tyler's (1990) finding of $41 \%$ of respondents for whom nothing alleviated the condition. Being in a quiet place was known to reduce tinnitus for $30 \%$ of the subjects. Although two respondents indicated that being in a noisy environment helped to ameliorate their tinnitus, they explained that the noise they were referring to was conversational noise as it helped them be less aware of the tinnitus. Very similar responses, although in a different rank order, were selected by respondents to Stouffer and Tyler's (1990) study. The only exception was "having just recently been in a quiet place" which replaced "wearing a hearing aid".

An important implication of these findings involves the planning of effective treatment programmes for tinnitus patients. In order to record instances where tinnitus severity is increased or decreased, patients are required to keep a tinnitus diary (O'Connor \& Zappia, 1993). This strategy is used to highlight situations which patients should either avoid or in which they should spend more time (Stouffer \& Tyler, 1990). Identifying associations or

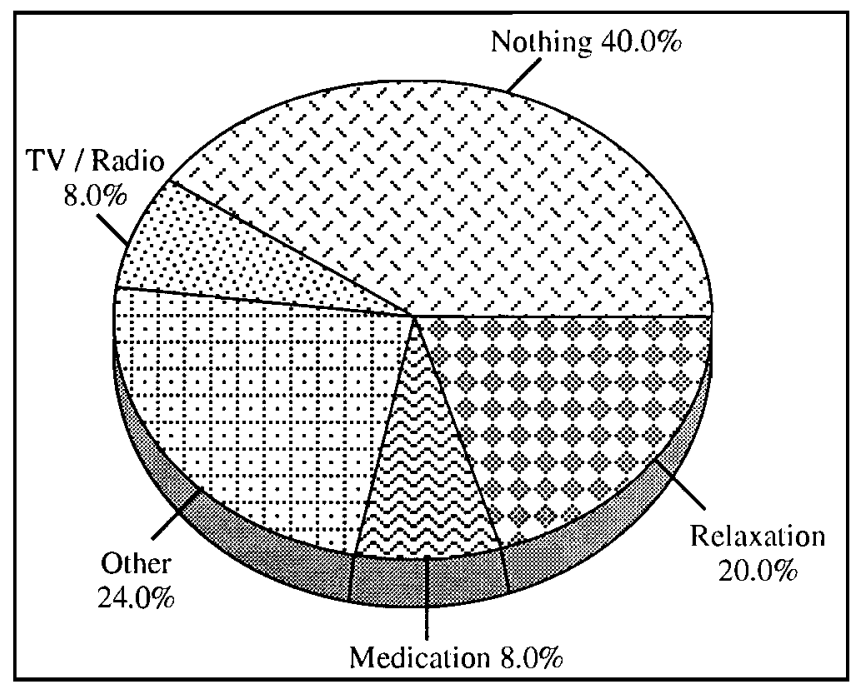

FIGURE 2.Categories of coping strategies employed by respondents $(\mathbf{N}=\mathbf{2 5})$

(Responses do not total 20 as respondents reported more than one way of coping)

TABLE 6: Factors perceived to make tinnitus worse ( $N=61)$

\begin{tabular}{|c|c|c|c|}
\hline Factors that aggravate tinnitus & No. of responses & Percentage of responses & Percentage of respondents \\
\hline Being in a noisy place & $\mathbf{9}$ & 14.8 & 45 \\
\hline Emotional/Mental stress & $\mathbf{9}$ & 14.8 & 40 \\
\hline Lack of sleep & $\mathbf{5}$ & 8.2 & $\mathbf{2 5}$ \\
\hline On first waking up & 5 & 8.2 & 25 \\
\hline Excitement & 4 & 6.5 & 15 \\
\hline Physical tiredness & 3 & 4.9 & 15 \\
\hline Drügs/Medicine & $\mathbf{3}$ & 4.9 & 15 \\
\hline Nothing & 3 & 4.9 & 15 \\
\hline Quiet place & $\mathbf{3}$ & 4.9 & 15 \\
\hline Change head position & 2 & $\mathbf{3 . 3}$ & 10 \\
\hline Recently in noise & 2 & 3.3 & 10 \\
\hline Relaxation & 2 & 3.3 & 10 \\
\hline Other & 11 & 18.0 & $\mathbf{5 0}$ \\
\hline
\end{tabular}

TABLE 7: Responses representing items selected that reduced tinnitus (N=25)

\begin{tabular}{|l|c|c|c|}
\hline $\begin{array}{l}\text { Factors that reduce } \\
\text { tinnitus }\end{array}$ & $\begin{array}{c}\text { The number of } \\
\text { responses }\end{array}$ & $\begin{array}{c}\text { Percentage of } \\
\text { responses }\end{array}$ & $\begin{array}{c}\text { Percentage of } \\
\text { respondents }\end{array}$ \\
\hline Nothing & 9 & 36 & 45 \\
Being in a quiet place & 6 & 24 & 30 \\
Sleep & 3 & 12 & 15 \\
Being in a noisy place & 3 & 12 & 15 \\
TV/radio & 2 & 8 & 10 \\
Wearing a hearing aid & 2 & 8 & 10 \\
\hline
\end{tabular}


possible cause and effect conditions, enables the patient to practically improve their quality of life and so contributes to their sense of control (O'Connor \& Zappia, 1993).

\section{COPING STRATEGIES}

The coping strategies were diverse with the main themes illustrated in Figure 2.

Some respondents preferred slightly noisier environments and would therefore turn on the TV/radio (10\%), wear their hearing aid $(5 \%)$, or keep busy $(5 \%)$. On the other hand, others preferred to relax or rest in a quiet environment $(20 \%)$ or switch off their hearing aid $(5 \%)$. However, although one respondent indicated that he tried to cope by relaxing, this strategy was often difficult so he tried to "channel my mind on pleasant thoughts". Some respondents attempted more drastic measures such as trying to take wax out of their ear $(5 \%)$, shaking their head or slamming it against a pillow (5\%), or taking medication $(10 \%)$, while the largest proportion of respondents, namely $45 \%$ reported doing nothing. As one person explained, "it is something you accept and learn to live with".

It has been found that beliefs about tinnitus may affect a patient's motivation to use coping strategies to deal with this condition (Erlandsson et al., 1992) which in turn may influence the level of distress produced by tinnitus (Lindberg, Scott, Melin \& Lyttkens, 1987). In their study, Dineen, Doyle and Bench (1997a) found no relationship between tinnitus symptoms, the length of time that tinnitus was present, beliefs about the nature and manageability of tinnitus and patients' perceived ability to cope with the condition. Regardless of their perceived ability to cope, those who were more distressed by tinnitus tended to use a wider range of coping behaviours (George \& Kemp, 1991). This result is supported by Dineen, Doyle and Bench's (1997a) finding that subjects who had previously sought help, used more coping behaviours than those who had not, suggesting that those who were emotionally distressed by their tinnitus were more likely to be more conscious of their attempts to cope, resulting in higher reported levels of emotion- and problem-focused coping behaviours.

The variability in coping strategies employed by respondents indicate the importance of developing tinnitus rehabilitation programmes that are sensitive to the variability amongst individuals (Dineen et al., 1997a).

\section{CONCLUSIONS}

The main finding that emerged from this study was that tinnitus impacted on respondents lives, although it varied from one individual to another. In general, tinnitus caused respondents to avoid noisy situations, have difficulty relaxing and have trouble in following conversations. It led to frustration, tenseness, irritability and depression. In addition, all respondents commented that tinnitus was variable. It was also found that tinnitus influenced respondents' health. The majority experienced dizziness and balance problems. There was also a concern that tinnitus would result in deafness.

Of the respondents who had previously sought medical advice, all had been told that there was nothing that could be done to alleviate the condition. Although the majority of respondents had learned to accept and live with their tinnitus it still had psychosocial consequences for them. This situation was highlighted by the finding that just under half the respondents had no idea what had caused their tinnitus. In addition, respondents were desirous of obtaining information regarding tinnitus.

It should be noted that the study was conducted on a small, non-probability sample preventing generalisation of the findings to the broader tinnitus population. A further limitation of the study was the fact that, due to practical problems experienced in recruiting sufficient subjects, there was no upper ceiling level in terms of age of subjects selected. Consequently respondents ranged in age from 60 to 93. De Santi and Obler (1991: 337) highlight the methodological problems inherent in including different sub-groups or cohorts such as the 'young old' and the 'old old' within the same research sample.

Nevertheless, despite these limitations, these findings are not only of relevance to the elderly population but have important implications for the education of health care professionals, management of tinnitus patients in general, public and patient awareness campaigns, the establishment of Tinnitus Self Help Groups, and further research.

\section{EDUCATION OF HEALTH CARE PROFESSIONALS}

According to Sweetow (1987a), tinnitus has largely been ignored or disregarded by members of the health professions, as they are uncomfortable in admitting their ignorance to patients who are desperately in need of knowledge. As a result many professionals have turned away tinnitus patients with the comment that there was nothing they could do about it; and they just had to learn to live with it (Sweetow, 1987a). Greater knowledge and awareness of tinnitus is therefore needed (Tyler, 1997b). Professional educátion in such diverse fields as audiology, medicine, nursing, otology, psychology and psychiatry (Shulman, 1987; Tyler 1997b), should increase understanding regarding the nature of tinnitus. It is further recommended that particular emphasis be placed on etiology, prevention, effects and rehabilitation strategies in undergraduate curricula as well as in continuing education workshops and training programmes (Tyler, 1997b). This knowledge could potentially assist in promoting appropriate referrals (Sweetow, 1987b; Tyler, $1997 \mathrm{~b})$, thereby ensuring better management of the patient. (Tyler et al., 1989).

\section{MANAGEMENT OF TINNITUS PATIENTS IN GENERAL}

A variety of treatments have been attempted for tinnitus over the years, including electrical stimulation, masking, acupuncture, medication, cognitive behaviour modification therapy, biofeedback, habituation therapy and counselling (Tyler \& Babin 1993). Since tinnitus is complex and diverse, affecting other life functions in addition to the auditory system, clinical management needs to focus not only on the alleviation of the symptom, but on the associated problems as well (Shulman, 1987; Sweetow, 1987a; Tyler et al., 1989; O'Connor \& Zappia, 1993). The aim should be tinnitus patient management as opposed to tinnitus management (Sweetow, 1987a). In order to achieve this aim and facilitate proper diagnosis and appropriate treatment, a multidisciplinary team approach needs to be utilised (Shulman, 1987). Moreover, tinnitus rehabilitation needs to be flexible reflecting the specific needs of the individual tinnitus patient (O'Connor \& Zappia, 1993; Tyler \& Babin, 1993). 


\section{PUBLIC AND PATIENT AWARENESS CAMPAIGNS}

The education of the general public regarding tinnitus is necessary in order to raise awareness of the nature and effects of tinnitus on the lives of tinnitus sufferers. This information would hopefully increase understanding of some of the problems experienced by patients, increase their support of clinical and research efforts, and more importantly, prepare potential tinnitus sufferers for the impact of tinnitus on their lives (Tyler, 1997b).

Beliefs about and attitudes toward tinnitus play an important role in rehabilitation (Erlandsson et al., 1992). For this reason, tinnitus patients require information to reduce their fears or provide reassurance that their tinnitus is not necessarily indicative of a life-threatening disease (Tyler \& Babin, 1993). Information about tinnitus would provide them with a realistic attitude concerning the condition and empower them to seek professional help (Tyler, 1997b). Most patients benefit from basic information on tinnitus as they come to realize that tinnitus is a real and common problem (Tyler, 1997a).

\section{THE ESTABLISHMENT OF TINNITUS SELF-HELP GROUPS}

In addition to the above clinical implications, the results suggest the need for the establishment of Tinnitus SelfHelp Groups. Self-help groups would enable patients to discuss the problems they experience as a result of tinnitus as well as the sounds they hear. Such discussion is usually helpful (Tyler \& Babin, 1993). Family members could be included in these discussions enabling them to realise the validity and severity of the problem (Tyler \& Babin, 1993). Self-help groups could also play a role in increasing public awareness of tinnitus.

\section{FURTHER RESEARCH}

According to Tyler (1997b), if one considers the widespread and devastating nature of tinnitus, research remains meagre. This situation is especially true in the South African context in which little, if any, research in this area appears to have been conducted. Until recently, tinnitus sufferers were generally told by their doctors that tinnitus was untreatable and that they simply have to live with it. Although many persons have accepted this advice, the extent of the problem has actually been obscured (Lindberg et al.,1984). Therefore, research is needed to determine the incidence of tinnitus in the South African population as well as its effect on quality of life. Hence there is a need to replicate the present study on larger samples more representative of sub-groups within the elderly population, different auditory pathologies, such as Menière's Disease, as well as the general population.

As there are as yet no highly effective treatments for the majority of tinnitus sufferers (George \& Kemp, 1991), research could evaluate the effects of different intervention strategies, such as masking, biofeedback, habituation therapy, counselling and so forth, on the perceptions of distress experienced by the tinnitus patient.

As mentioned previously, individual tinnitus patients react differently to their tinnitus, suggesting that personality might play a role in the perception of and reaction to tinnitus (House \& House, 1987). Thus, further research could investigate the relationship between personality and the subjective experience of tinnitus.

Largely anecdotal evidence exists regarding the effects of caffeine, alcohol and nicotine on tinnitus (Slater \& Terry, 1987). Hence there is a need for further empirical research in this area.

In conclusion, this study has highlighted the psychosocial effects of tinnitus. Tyler (1993) states that tinnitus cannot simply be regarded as a disorder resulting from an auditory system pathology, or an impairment due to the auditoryperceptual characteristics. Tinnitus can cause a disability in terms of sleep, concentration and understanding of speech, resulting in a handicap as lifestyle is affected (Tyler, 1993). Hence, our understanding of the nature of tinnitus needs to include its often disabling and handicapping nature (Tyler, 1993).

\section{REFERENCES}

Axelsson, A. \& Ringdahl, A. (1989). Tinnitus: a study of its prevalence and characteristics. British Journal of Audiology. $23,53-62$.

Baker, T. L. (1988). Doing social research. New York; McGrawHill Book Co.

Botwinick, J. (1984). Aging and behavior: A comprehensive integration of research findings (Third Edition). New York: Springer Publishing Company.

Chodzko-Zajko, W. J. (1997). Normal aging and human physiology. Seminars in Speech and Language. 18. 95-105.

Chung, D. Y., Gannon, R. P. \& Mason, K. (1984). Factors affecting the prevalence of tinnitus. Audiology. 23. 441-452.

Coles, R. R. A. (1987). Tinnitus and its management. In S. D. G. Stevens \& A. G. Kerr (Eds.). Scott-Brown's Otolaryngology. Guildford: Butterworth Scientific.

de Santi, S. \& Obler, L. K. (1991). Methodological issues in research on aging and language. In D. Ripich (Ed.). Handbook of geriatric communication disorders. (pp. 333-347). Austen: Pro-Ed.

de Vaus, D.A. (1991). Surveys in social research. London: Allen \& Unwin.

Dineen, R., Doyle, J. \& Bench, J. (1997a). Audiological and psychological characteristics of a group of tinnitus sufferers, prior to tinnitus management training. British Journal of Audiology. 31, 27-38.

Dineen, R., Doyle, J. \& Bench, J. (1997b). Managing tinnitus: A comparison of different approaches to tinnitus management training.

Dooley, D. (1995). Social research methods. (Third ed.). Englewood Cliffs: Prentice-Hall.

Erlandsson, S. I., Hallberg, L. R. M. \& Axelsson, A.' (1992). Psychological and audiological correlates of perceived tinnitus severity. Audiology. 31, 168-179.

George, R. N. \& Kemp, S. (1991). A survey of New Zealanders with tinnitus. British Journal of Audiology. 25, 331-336.

Hallam, R. S., Jakes, S.C. \& Hinchcliffe, R. (1988). Cognitive variables in tinnitus annoyance. British Journal of Clinical Psychology. 27, 213-222.

Hallam, R., Rachman, S. \& Hinchcliffe, R. (1984). Psychological aspects of tinnitus. In S. Rachman (Ed.). Contributions to medical psychology, Volume 3. (pp. 31-50). Oxford: Pergamon Press.

Hellman, R. P. \& Meiselman, C. H. (1988). Prediction of individual loudness exponents from cross-modality matching. Journal of Speech and Hearing Research, 31, 605-615.

House, P. R. \& House J. W. (1987). The tinnitus patient: Personality and biofeedback treatment. Seminars in hearing. 8, 15-19.

Jackson, P. (1983). Tinnitus in the elderly. In R. Hinchcliffe (Ed). Hearing and balance in the elderly. (pp. 159-175). London: Churchill Livingstone.

Jakes, S. C., Hallam, R. S., Chambers, C. \& Hinchcliffe, R. (1985). Audiology. 24, 195- 206.

Kuk, F., Tyler, R. S., Russel, D. \& Jordan, H. (1990). The psychometric properties of a tinnitus handicap questionnaire. Ear and Hearing, 11, 434-442.

Lindberg, P., Lyttkens, L., Melin, L. \& Scott, B. (1984). Tinnitus: 
incidence and handicap. Scandinavian Audiology. 13, 287-291.

Lindberg, P., Scott, B., Melin, L. \& Lyttkens, L. (1987). Longterm effects of psychological treatment of tinnitus. Scandinavian Audiology. 16, 167-172.

Lubinski, R. \& Welland, R. J. (1997). Normal aging and environmental effects on communication. Seminars in Speech and Language. 18, 107-125.

Maddox, G. L. (1978). The social and cultural context of aging. In G. Usdin \& C. K. Hofling (Eds.). Aging: the process and the people. New York: Brunner/Mazel Publishers.

McCall, R. M. (1994). Fundamental statistics for behavioral sciences (Sixth edition). Fort Worth: Harcourt Brace College Publishers.

Miekle, M. \& Griest, S. (1987). The perceived localization of tinnitus. In H. Feldman (Ed.). Proceedings of the III International Tinnitus Seminar. Karlsruhe: Harsch Verlag.

Miller, J. M., Dolan, D. F., Raphael, Y. \& Altschuler, R. A. (1998). Interactive effects of aging with noise induced hearing loss. Scandinavian Audiology. 27, (Suppl 48), 53-61.

Norton, S. J., Schmidt, A. R. \& Stover, L. J. (1990). Tinnitus and otoacoustic emissions: is there a link? Ear and Hearing, 11, 159-166.

O'Connor, C. A. \& Zappia, J. J. (1993). Management of the tinnitus patient. J.A.R.A.. 26, 25-38.

Reader's Digest (1984). Great Illustrated Dictionary, Volume 2 $(L-Z)$. London: The Reader's Digest Association Limited.

Scott, B., Lindberg, P., Melin, L: \& Lyttkens, L. (1990). Predictors of tinnitus discomfort, adaptation and subjective loudness. British Journal of Audiology, 24, 51-62.

Shepard, N. T. \& Telian, S. A. (1994). Evaluation of balance system function. In J. Katz (Ed.). Handbook of clinical audiology (Fourth edition). (pp.424-447). Baltimore: Williams and Wilkins.

Shulman, A. (1987). Medical audiological evaluation of the tinnitus patient. Seminars in hearing. 8, 7-14.

Singleton, R. Straits, B. C. \& Straits, M. M. (1993). Approaches to social research (Second edition). New York: Oxford University Press.

Slater, R. \& Terry, M. (1987). Tinnitus: A guide for sufferers and professionals. London: Croom Helm.
Spirduso, W.W \& Gilliam-MacRae, P., (1991). Physical activity and quality of life in the frail elderly. In J.E. Birren, J.E. Lubben, J.C. Rowe, \& D.E. Deutchman (Eds.) The concept and measurement of quality of life in the frail elderly. San Diego: Academic Press, Inc.

Stouffer, J. L. \& Tyler, R. S. (1990). Characterization of tinnitus by tinnitus patients. Journal of Speech and Hearing Disorders. $55,439-453$

Sweetow, R. W. (1987a). Comprehensive tinnitus patient management. Seminars in hearing. 8, 71-74.

Sweetow, R. W. (1987b). Preface. Seminars in hearing. 8 (1).

The White Paper for Social Welfare. (1997). Government Gazette Notice 1108 of 1997. Pretoria: Department of Welfare.

The White Paper for the Transformation of the Health System in South Africa. (1997). Government Gazette, Notice 667 of 1997. Pretoria: Department of Health

Tyler, R. S. (1993). Tinnitus disability and handicap questionnaires. Seminars in Hearing. 14, 377-384.

Tyler, R. S. (1997a). Tinnitus: Current theories and treatments. The Hearing Journal. 50. 10- 19

Tyler, R. S. (1997b). Perspectives on tinnitus. British Journal of Audiology. 31, 381-386.

Tyler, R. S. \& Babin, R. W. (1993). Tinnitus. In C. W. Cummings (Ed). Otolaryngology: head and neck surgery (Second edition). Baltimore: Mosby-Year Book, Inc.

Tyler, R. S. \& Baker, L. J. (1983). Difficulties experienced by tinnitus sufferers. Journal of Speech and Hearing Disorders. $48,150-154$

Tyler, R. S., Aran, J-M. \& Dauman, R. (1992). Recent advances in tinnitus. American Journal of Audiology. 1, 36-44.

Tyler, R. S., Stouffer, J. L. \& Schum, R. (1989). Audiological rehabilitation of the tinnitus client. J.A.R.A. 22, 30-42

Ventry, I. \& Schiavetti, N. (1980). Evaluating research in speech pathology and audiology: A guide for clinicians and students. Reading: Addison-Wesley Publishing Co.

Wilson, P. H., Henry. J., Bowen M. \& Haralambous, G. (1991). Tinnitus Reaction Questionnaire: Psychometric properties of a measure of distress associated with tinnitus. Journal of Speech and Hearing Research. 34, 197-201.

\section{APPENDIX A \\ TINNITUS QUESTIONNAIRE}

(Adapted from Stouffer \& Tyler, 1990 and Wilson et al:, 1991)

\section{A: Biographical Information}

1. Please fill in the following information:

- age

- previous occupation

- gender

\section{B: The characteristics of your tinnitus}

2. Where is your tinnitus? (Please circle only ONE ANSWER)

- left ear

- right ear

- both ears equally

- both ears, but worse in the left

- both ears, but worse in the right
- in the head but no exact place

- more in the right side of the head

- more in the left side of the head

- outside of the head

- middle of the head

3. Which of these qualities best describes your tinnitus?

$\begin{array}{ll}\text { - buzzing } & \text { - humming } \\ \text { - clanging } & \text { - musical note } \\ \text { - clicking } & \text { - popping } \\ \text { - crackling } & \text { - pounding } \\ \text { - cricket-like } & \text { - pulsing } \\ \text { - hissing } & \text { - ringing }\end{array}$

- roaring

- rushing

- steam whistle

- throbbing

- whistling

- whooshing 
4. Describe the most prominent PITCH of your tinnitus by circling $\boldsymbol{O N E}$ of the numbers below. Number 1 is like a $V E R Y$ LOW deep male voice, and number 10 is like a VERY HIGH pitched whistle.

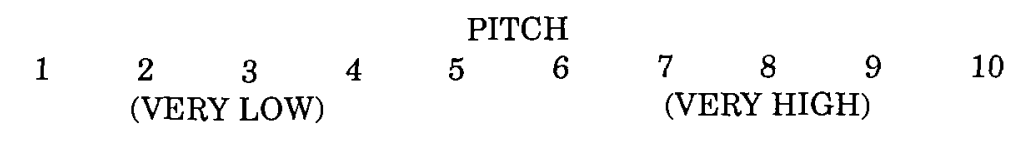

5. Describe the LOUDNESS of your tinnitus by circling one of the numbers below. Number 1 is VERY FAINT tinnitus, and number 10 is VERY LOVD tinnitus.

\begin{tabular}{llllllllll}
\multicolumn{1}{c}{ LOUDNESS } \\
1 & 2 & 3 & 4 & 5 & 6 & 7 & 8 & 9 & 10
\end{tabular}

6. How many months / years have you had tinnitus?

7. How often are you bothered by your tinnitus?

\section{C: The effects of tinnitus on your lifestyle}

8. For the following items, please rate how tinnitus has affected your LIFESTYLE. Circle the relevant number where: 1 = never; $2=$ sometimes; $3=$ often; and $4=$ all the time.

- My tinnitus has interfered with my enjoyment of life.

- My tinnitus has caused me to avoid social situations.

- My tinnitus has caused me to avoid quiet situations.

- My tinnitus makes it hard for me to concentrate.

- My tinnitus makes it hard for me to relax.

- My tinnitus has interfered with my ability to work.

- My tinnitus has caused me to avoid noisy situations.

- My tinnitus has interfered with my sleep.

- My tinnitus makes it hard for me to follow a conversation.

- My tinnitus makes me feel tired.

- My tinnitus has interfered with the quality of my relationships.

- My tinnitus makes it hard for me to understand speech.

$\begin{array}{lll}2 & 3 & 4 \\ 2 & 3 & 4 \\ 2 & 3 & 4 \\ 2 & 3 & 4 \\ 2 & 3 & 4 \\ 2 & 3 & 4 \\ 2 & 3 & 4 \\ 2 & 3 & 4 \\ 2 & 3 & 4 \\ 2 & 3 & 4 \\ 2 & 3 & 4 \\ 2 & 3 & 4\end{array}$

9. For the following items< please rate how tinnitus AFFECTS you. Circle the relevant number where:

1 = never; 2 = sometimes; 3 = often; and 4 = never.

- My tinnitus has made me feel depressed.

- My tinnitus has made me feel unhappy.

- My tinnitus has made me feel tense.

- My tinnitus has made me feel irritable.

- My tinnitus has made me feel angry.

- My tinnitus has made me feel annoyed.

- My tinnitus has made me feel confused.

- My tinnitus has made me feel helpless.

- My tinnitus has made me feel frustrated.

- My tinnitus has made me feel hopeless about the future.

- My tinnitus has made me feel tormented.

- My tinnitus has led me to cry.

- My tinnitus has "driven me crazy".

- My tinnitus has led me to think about suicide.

$\begin{array}{lll}2 & 3 & 4 \\ 2 & 3 & 4 \\ 2 & 3 & 4 \\ 2 & 3 & 4 \\ 2 & 3 & 4 \\ 2 & 3 & 4 \\ 2 & 3 & 4 \\ 2 & 3 & 4 \\ 2 & 3 & 4 \\ 2 & 3 & 4 \\ 2 & 3 & 4 \\ 2 & 3 & 4 \\ 2 & 3 & 4 \\ 2 & 3 & 4\end{array}$

10. For the following items, please indicate how tinnitus has affected your general $\boldsymbol{H E A L T H}$ by ticking ALL those that apply to you:

- My tinnitus has caused me to become dependent on drugs.

- My tinnitus causes me to experience pain / headaches.

- My tinnitus makes me feel dizzy.

- My tinnitus causes me to lose my balance.

- I am concerned that my tinnitus is a symptom of a much worse disease.

- I am concerned that I might go deaf because of my tinnitus.

\section{D: The cause/s of tinnitus}

11. What do you think originally caused your tinnitus? 


\section{E: Factors influencing your tinnitus}

12. When you have your tinnitus, which of the following makes it WORSE? Tick $\boldsymbol{A L L}$ those that apply to you.

- alcohol

- being in a noisy place

- being in a quiet place

- changing head position

- having just recently been in a noisy place

- having just recently worn a hearing aid

- constipation

- emotional / mental stress

- lack of sleep

- relaxation

- food
- smoking

- coffee / tea

- drugs / medicine

- sudden physical activity

- when you are excited

- when you are tired from doing physical work

- while you are wearing a hearing aid

- when you first wake up in the morning

- listening to the radio / TV

- nothing makes it worse

- OTHER (PLEASE SPECIFY)

13. Which of the following REDUCES your tinnitus? Tick $\boldsymbol{A} \boldsymbol{L} \boldsymbol{L}$ of the answers that apply to you.

- alcohol

- being in a noisy place

- being in a quiet place

- coffee / tea

- drugs / medicine

- smoking

- nothing reduces my tinnitus
- having just recently been in a noisy place

- having just recently worn a hearing aid

- listening to the television or radio

- emotional / mental stress

- sleep

- food

- OTHER (PLEASE SPECIFY)

\section{F: Coping strategies}

14. What do you do to help you COPE with your tinnitus? (i.e., what do you do when your tinnitus is bad?)

\section{G: Other}

15. Do you have any other comments you would like to make about your tinnitus?

Thank you very much for your cooperation.

1. Primary diagnosis (tick only ONE)

- Noise-induced hearing loss

- Presbycusis

- Meniere's disease

- Middle ear disorder (please specify)

- Retrocochlear (please spécify)

- Normal hearing (please specify)

- Unknown

- Other (please specify)

2. Primary complaint (tick only ONE)

- hearing loss

- dizziness

- tinnitus

- pain or headaches

- other (please specify)

3. Hearing thresholds

Left ear

$1000 \mathrm{~Hz}$

$4000 \mathrm{~Hz}$ 